\title{
Comparative Analysis of Intelligent Controller Based MPPT for Photovoltaic System with Super Lift Boost Converter
}

\author{
Palanivel MANIKANNAN, Kaithmalai UDHAYAKUMAR, Parthasarathi PUGAZHENDIRAN
}

\begin{abstract}
In recent years, the electrical energy demand increases gradually and the power generation does not meet the demand due to lack of fossil fuel and environmental issues. The only solution is to use renewable energy sources for generating electricity and meet the consumers demand. In this paper, photovoltaic power system analyses their performance under various weather conditions. The objective of this paper is comparing the different intelligent controllers such as Fuzzy, ANFIS and Hybrid Fuzzy \& Firefly Algorithm (HFFA) for Maximum Power Point Tracking (MPPT) of 100 Watts PV system using a Super Lift Boost Converter (SLBC). The proposed intelligent controller is designed and simulated in MATLAB environment under various weather conditions. The simulation results have been analyzed and the performance of the proposed model evaluated with changing irradiation conditions. Finally, the performance of Hybrid Fuzzy and firefly based MPPT has been suggested as the optimum controller for the photovoltaic system.
\end{abstract}

Keywords: ANFIS; Fuzzy Logic; HFFA; MATLAB; MPPT; photovoltaic; super-lift boost converter

\section{INTRODUCTION}

The generation of electric power from a photovoltaic cell (PV) essentially relies upon the adjustment in atmospheric terms, such as the temperature, irradiance, and the associated loads, with the terminals to the PV system. To enhance the generation of PV, a suitable framework for MPPT is set up, which anticipates developing the most extreme power that is harvested by PV. The MPPT framework is consolidated with PV to drive it to work at its maximum Power point (MPP). This MPPT framework has three sections, the equipment part which is predominantly used in DC-DC converter for disengaging PV panel. The photovoltaic panel part, which changes over the sunlight, is based on the detailed information of current and voltage to perform power into electrical power. In the control section, the detailed information of current and voltage is to perform the converter with the changes of impedance in the PV panel $[1,2]$. The next part of the framework, the PV panel with MPPT attains the synchronization of connected loads and extracts the maximum power. Hence, the solar power tracking efficiency becomes increased. To endorse the PV system that is operating at MPP a chopper (DC-DC converter) along with an MPPT controller is interleaved within the PV panel and load. The open circuit voltage method, short circuit current method, Ripple Correlation Control (RCC), Perturb and Observe (P \& O), Incremental Conductance (INC) and sliding mode control methods are the existing MPPT techniques for the proposed work. Traditional hill climbing approach is simple and flexible to adapt. But it has a few difficulties like fluctuations of operating point nearby MPPT, entails long duration to estimate MPP, rapidly changing weather conditions and ineffective operation under Partial Shading Circumstances (PSC); it decreases the complete system efficiency. Open circuit voltage $\left(V_{\mathrm{oc}}\right)$ based MPPT is basic and easy to implement, yet it is essential to estimate the $V_{\text {oc }}$ intermittently by commutating the converter instantly, results in a momentary loss of power [3-6]. The MPPT is working with the short circuit current approach and is easy to execute with only one sensor, but instantly occurring the short-circuit of PV module is a prerequisite to estimate the short circuit current $\left(I_{\mathrm{sc}}\right)$. The state space based MPPT and linearization based MPPT methods are transforming the non-linear current and power equations into linear, then it tracks the MPP. In temperature based MPPT method, a minimum number of transducers are used to trace MPP. The majority of the MPPT methods are specified previously to attain the maximum power point during the rapidly fluctuating climatic circumstances and partial shading conditions. The MPPT with Soft Computing (SC) techniques are familiarized to identify the MPP under uncertain climatic conditions effectively [18]. The best features of soft computing methods are predicted to accomplish tractability, flexibility to climate, quick changes in irradiance, low cost, instability, tolerance for imprecision and power.

In soft computing methods, the Fuzzy Logic Control (FLC) is an ultimate technique compared to the conventional methods. In FLC, there is no need of any mathematical modeling of a system and therefore, the nonlinear systems are dealt with easily. The process of an FLC is realized in three different phases. They are fuzzification, rule-based table and defuzzification. The errors are assessed by using irradiance, PV voltage, PV current, temperature, and output power [20-22]. The actual PV voltage and the actual PV current are the inputs of FLC. Based on the fuzzy logic controller output, the converter gets the Pulse Width Modulation (PWM) signal in various circumstances like irradiance, temperature and etc.

The Artificial Intelligence (AI) based approach is the most appropriate one for enhancing the dynamic response of the MPPT. Nowadays, the unification of Artificial Neural Networks and Fuzzy Logic are known as ANFIS, which is used in most of the automated computational applications in industry. It associates with the merits of both fuzzy and artificial neural network $[6,7]$. So, it can be effectively adopted for nonlinear I-V responses of the PV panels. It has the excellent features like quick response, flexibility and calculating stimulus solutions for the MPPT problems $[11,13]$.

This paper ventured a novel technique of Firefly Algorithm (FA) by envisaging the points of membership functions of FLC for MPPT in photovoltaic systems using Super Lift Boost Converter (SLBC). In firefly algorithm, the coefficients $\alpha, \beta$ and $\gamma$ are fixed to get every recurrence 
to attain rapid merging. The suggested firefly algorithm is used for generating the PWM pulses by adjusting the fuzzy logic controller to achieve the optimum result for PV using MPPT. The simulation result of the suggested Hybrid Fuzzy \& Firefly Algorithm (HFFA) is compared with FLC and ANFIS control methods to validate the response of the projected technique [15-17]. In this paper, the intelligent controller based MPPT techniques are incorporated with super-lift boost converter for attaining the maximum power output from the PV panel. The super-lift boost converters are used to improve the voltage transfer gain to a great extent. This investigation presents a modified super-lift boost converter that actualizes the super-lift operation too and its voltage transfer gain improves step by step in geometric development.

This enhanced transfer gain due to the super lift boost converter has been compared with the different intelligent controllers' response such as Fuzzy, ANFIS and hybrid fuzzy \& Firefly algorithm for MPPT of 100 Watts PV system.

The organization of this work is presented as follows; section 2 presents the super-lift boost converter and its operation with necessary equations. Section 3 depicts the different proposed MPPT controllers in detail. Section 4 illustrates the simulation model and its results for different operating conditions. Finally, the findings of this work have been presented as a conclusion with optimized operating conditions of PV with different MPPT controllers in section 5 .

\section{SUPER LIFT BOOST CONVERTER}

Super-lift practice is more influential than CUK and SEPIC converters which makes it powerful; it can generate the arithmetic progression output voltage and it has a high efficiency and power density $[10,11]$. A Voltage-lift DCDC Chopper (converter) operates with high voltage transfer gain and large voltage amplification in the first quadrant. This converter is used by industrial and domestic applications but it is still under research.
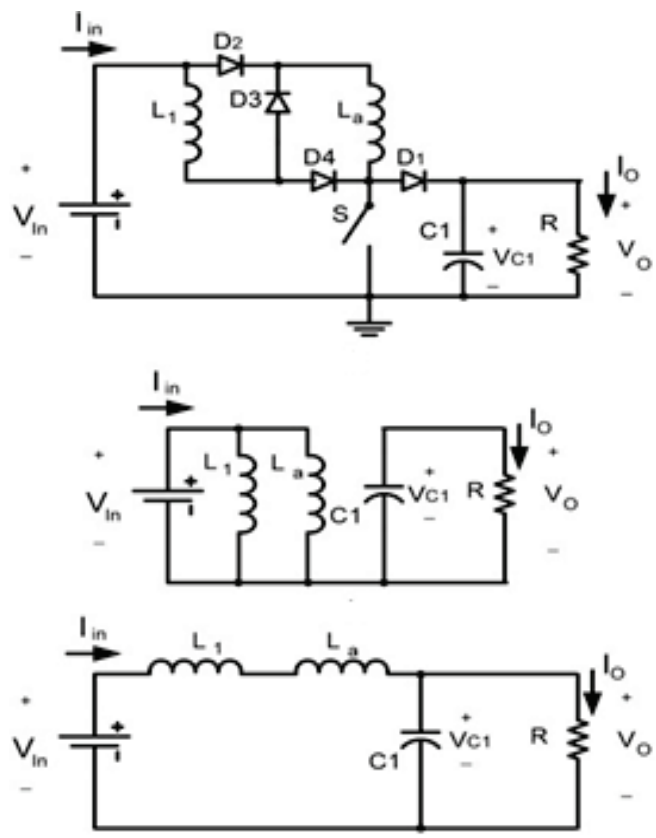

Figure 1 Super lift Boost Converter
The actual fundamental super lift boost converter circuit (called as an elementary circuit) and its equivalent circuits under two operating conditions (ON and OFF) are presented in Fig. 1. For obtaining the voltage-lift, one more set of $L_{\mathrm{a}}$ and $D_{2}-D_{4}$ has been introduced for conventional boost converters $\left(L_{1}, D_{1}, C_{1}\right.$ and $R$ are the original components). The inductor $L_{\mathrm{a}}$ included in the proposed circuit has identical values of $L$ and $L_{1}$ [9]. It is essential for the continuous current flow in the circuit as soon as the switch is under turn-off condition. It is expressed that $L_{1}=$ $L_{\mathrm{a}}$ under switching-on period $k T$, so the current flow through $L_{1}\left(i_{L 1}\right)$ is boosted with the input voltage $\left(V_{\text {in }}\right)$. During this operating period, the $D_{2}$ and $D_{4}$ are in ON condition and $D_{1}$ and $D_{3}$ are in OFF condition (blocking mode). Therefore, the $i_{L 1}$ current starts to decrease with $\left(V_{0}-V_{\text {in }}\right)$ during its off period $(1-k) T$ through inductors $\left(L_{1}+L_{\mathrm{a}}\right)$. Hence, $D_{1}-D_{3}$ are conducted and $D_{2}-D_{4}$ are blocked.

Therefore, inductor ripple current $i_{L 1}$ is:

$$
\Delta i_{L 1}=\frac{V_{0}-V_{\text {in }}}{L_{\mathrm{a}}-L_{1}}(1-k T)
$$

The voltage transfer gain can be expressed as:

$G=\frac{V_{0}}{V_{\text {in }}}=\frac{1+k}{1-k}$

Addition of inductor $q\left(L_{\mathrm{b}}\right)$ with the basic super lift boost converter results in the repeated operation and it is as shown in Fig. 2.

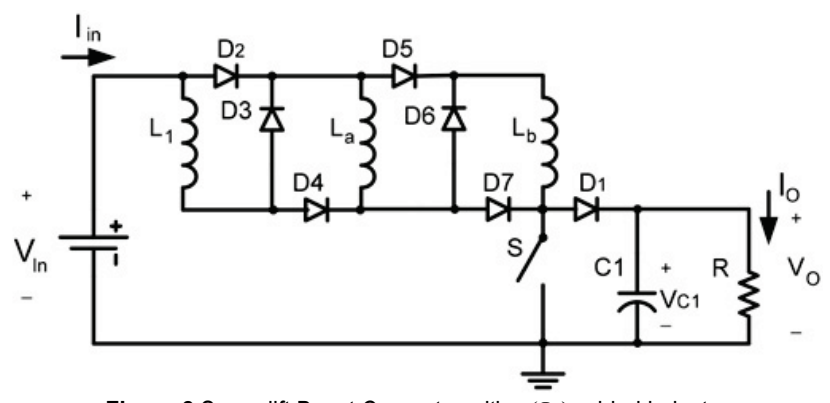

Figure 2 Super lift Boost Converter with $q\left(\bar{L}_{\mathrm{b}}\right)$ added inductor

Table 1 VTG's Comparison of different converters

\begin{tabular}{|c|c|c|c|c|c|c|c|c|}
\hline Duty cycle & 0,1 & 0,1 & 0,2 & 0,5 & 0,6 & 0,75 & 0,8 & 0,9 \\
\hline$G_{\mathrm{plf}}=\frac{k}{1-k}$ & 0 & 0,11 & 0,25 & 1 & 1.5 & 3 & 4 & 9 \\
\hline$G_{\mathrm{pf}}=\frac{k}{1-k}$ & 0 & 1,11 & 1,25 & 2 & 2.5 & 4 & 5 & 10 \\
\hline$G_{\mathrm{pslf}}=\frac{2-k}{1-k}$ & 1 & 2,11 & 2,25 & 3 & 3.5 & 5 & 6 & 11 \\
\hline$G_{\mathrm{f} 1}=\frac{1+k}{1-k}$ & 2 & 1,22 & 1,5 & 3 & 4 & 7 & 9 & 19 \\
\hline$G_{\mathrm{f} 2}=\frac{1+2 k}{1-k}$ & 1 & 1,33 & 1,75 & 4 & 5.5 & 10 & 13 & 28 \\
\hline$G_{\mathrm{f} 3}=\frac{1+3 k}{1-k}$ & 1 & 1,44 & 2 & 5 & 7 & 13 & 17 & 37 \\
\hline
\end{tabular}

The VTG of elementary circuit with $q$. 
Added inductors is:

$G_{\mathrm{f}}=\frac{V_{0}}{V_{\text {in }}}=\frac{1+q k}{1-k}$

When $q=1$,

$G_{\mathrm{f}}=\frac{V_{0}}{V_{\text {in }}}=\frac{1+k}{1-k}$

When $q=2$,

$G_{\mathrm{f}}=\frac{V_{0}}{V_{\text {in }}}=\frac{1+2 k}{1-k}$

When $q=3$,

$G_{\mathrm{f}}=\frac{V_{0}}{V_{\text {in }}}=\frac{1+3 k}{1-k}$

where: $q$ - number of inductors in each stage; $k$ - duty cycle; $G_{\mathrm{f}}-\mathrm{VTG}$ of fundamental Circuit.

By using the fundamental VTG equation for different boost converter topologies like fundamental super-lift boost converters, positive output Luo and super lift Luo converter, boost converter with different duty cycles is computed and tabulated in Tab. 1. From this, it is clearly shown that the super-lift boost converters are more superior (when $k>0,5$ ) than the existing converters.

\section{MPPT CONTROLLERS}

The renewable energy sources play an important role to meet the consumer power demand due to their abundant availability and a smaller amount of impact on the environment. The main hurdle in PV energy expansion is the investment cost of the PV power system implementation. The PV energy generation is continuously varying throughout the day due to the changing of weather condition. The efficiency of power generation is very low (the range of efficiency is only $9-17 \%$ in low irradiation regions). Therefore, MPPT technologies have an important role to operate the $\mathrm{PV}$ with the maximum power generation at various weather conditions [12-16]. The different MPPT techniques are established with respect to usage of equipment and cost. In this paper, different intelligent controller based MPPT techniques have been designed and investigated.

\subsection{Fuzzy Logic Based MPPT Controller}

In this method, the proposed fuzzy logic controller has been designed $[3,4]$ with two inputs, namely, actual PV current and PV voltage are shown in Fig. 3, Fig. 4, and Fig. 5. The trapezoidal method is used to convert these parameters to a fuzzy set. According to the time-varying voltage and current as an input to the fuzzy rule table, the rules are used to select the duty cycles to the converters which is shown in Fig. 6 and Fig. 7. Finally, the fuzzy set value is converted into a crisp set using the center of gravity method, and then the signal is fed into a PWM generator to generate the pulses for DC-DC converter [22].

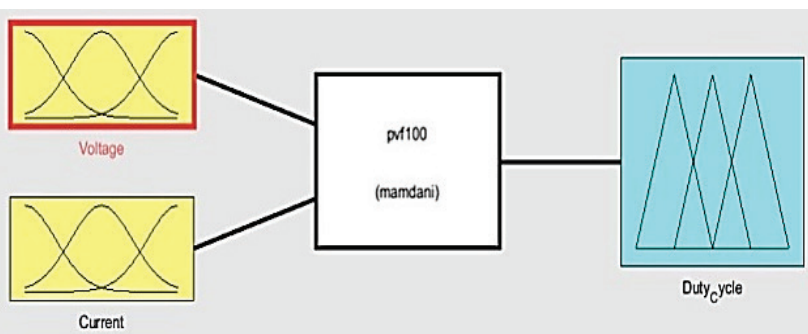

Figure 3 Proposed Fuzzy based MPPT Controller for DC-DC super lift converter

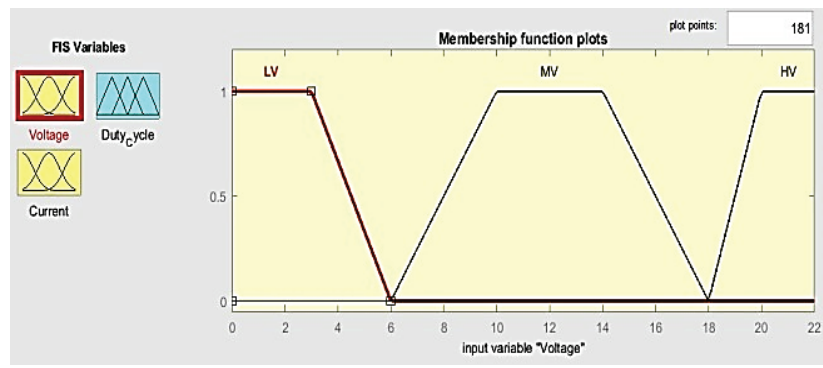

Figure 4 Input fuzzy Membership function-PV Voltage

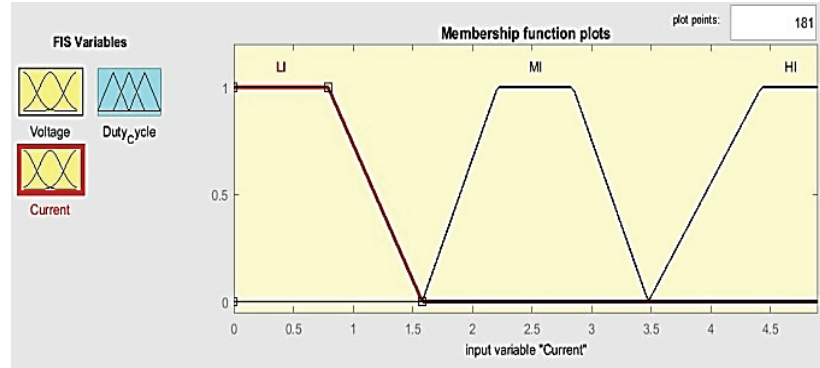

Figure 5 Input fuzzy Membership function - Current

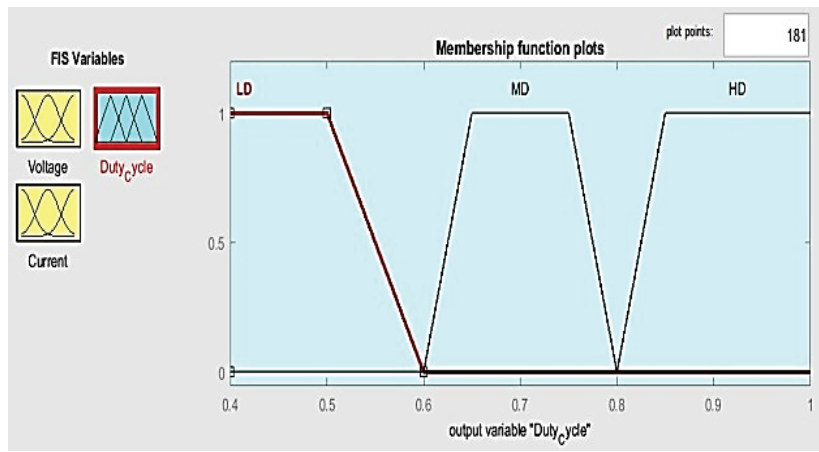

Figure 6 Output fuzzy Membership function - Modulation index (duty cycle)
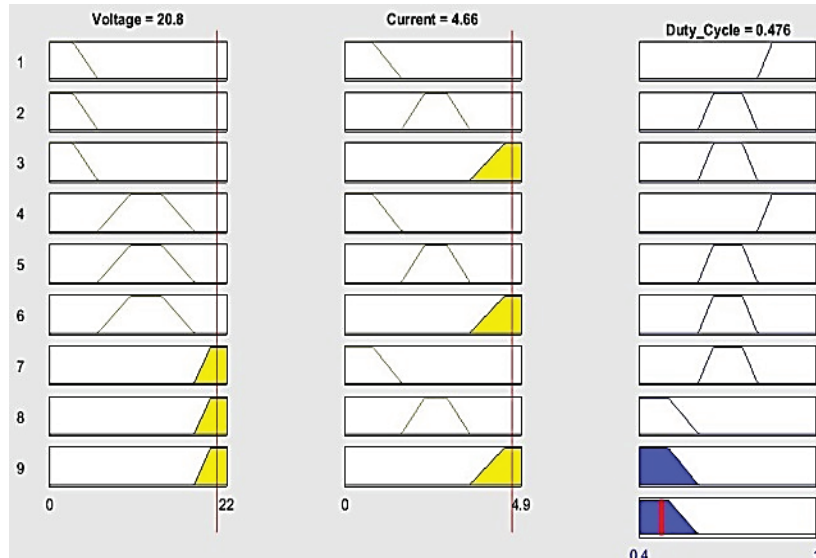

Figure 7 Fuzzy rules for MPPT controlle 


\subsection{ANFIS Based MPPT Controller}

In this method, ANFIS logic controller is designed and simulated in MATLAB environment as shown in Fig. 17. The ANFIS controller has two inputs namely; actual PV current, PV voltage and one output called duty cycle is shown in Fig. 8. The proposed ANFIS controller has been trained based on the input parameter and its respected output is presented in Fig. 9. The ANFIS controller has been analyzed based on the error value during training, as shown in Fig. 10. The ANFIS controller automatically selects the input and output membership values based on their training, then it generates the rule for selecting the duty cycle as shown in Fig. 11. Finally, ANFIS output signal is fed into a PWM generator to generate the pulse for super lift boost converter [5].

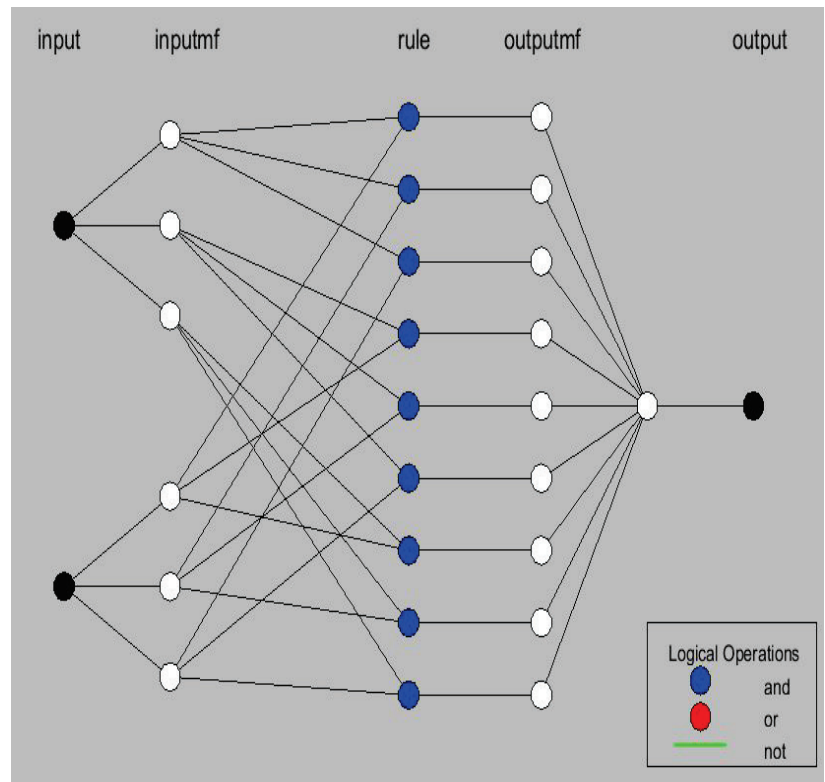

Figure 8 ANFIS Controller Network for MPPT controller

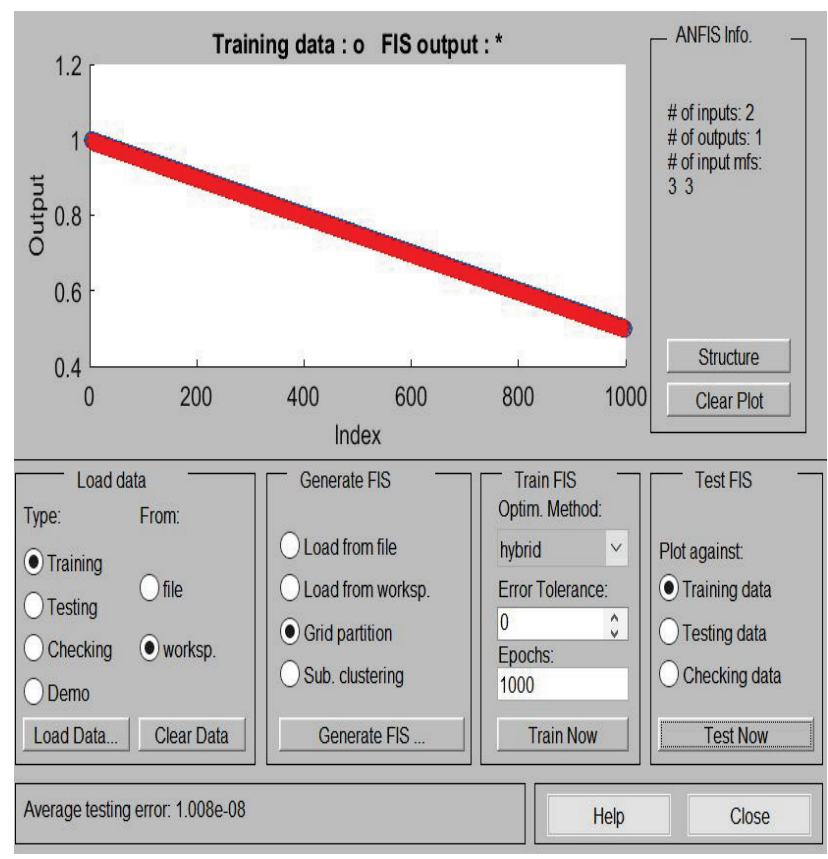

Figure 9 ANFIS training for MPPT controller

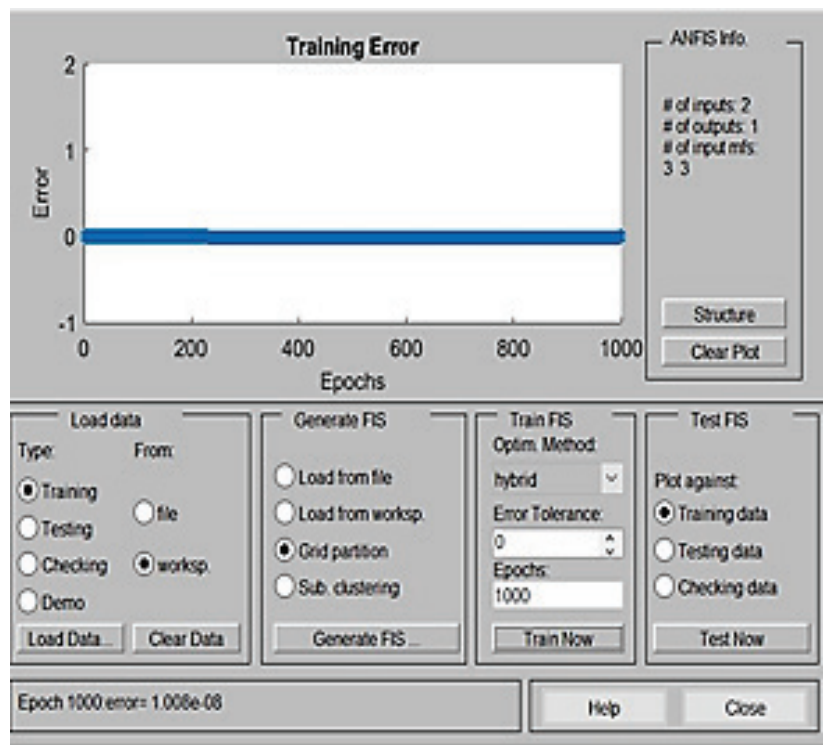

Figure 10 ANFIS training error for MPPT controller
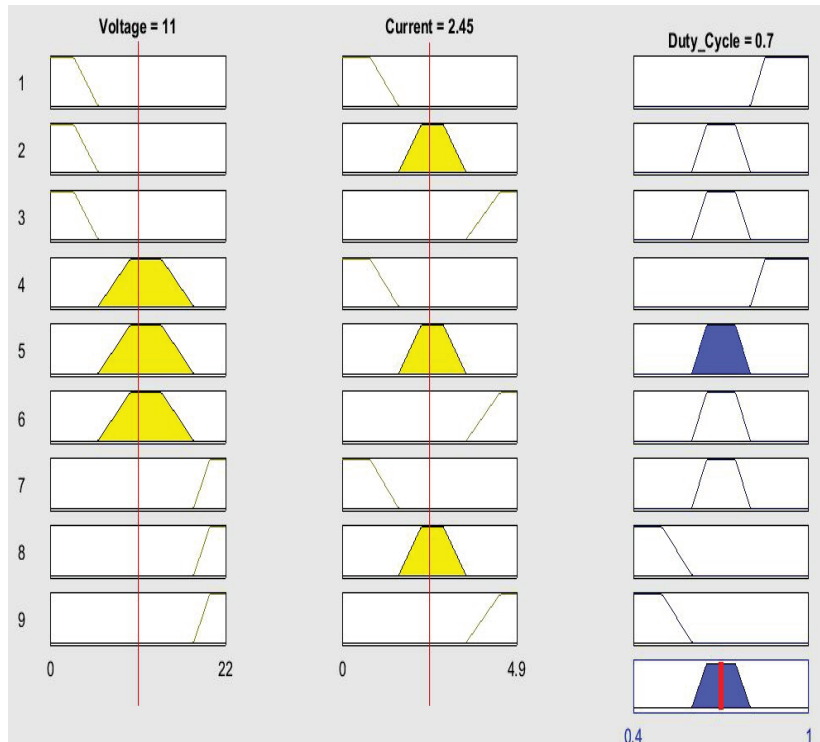

Figure 11 ANFIS rules for MPPT

\subsection{Hybrid Firefly and Fuzzy MPPT}

The proposed hybrid fuzzy and firefly controller has been designed for MPPT controller (100 W PV systems) and is shown in Fig. 12. The two major intelligent controllers have been designed to optimize the duty cycle of the DC-DC converter and achieve the objective of MPPT techniques [15-17]. The following steps are used for MPPT controller design:

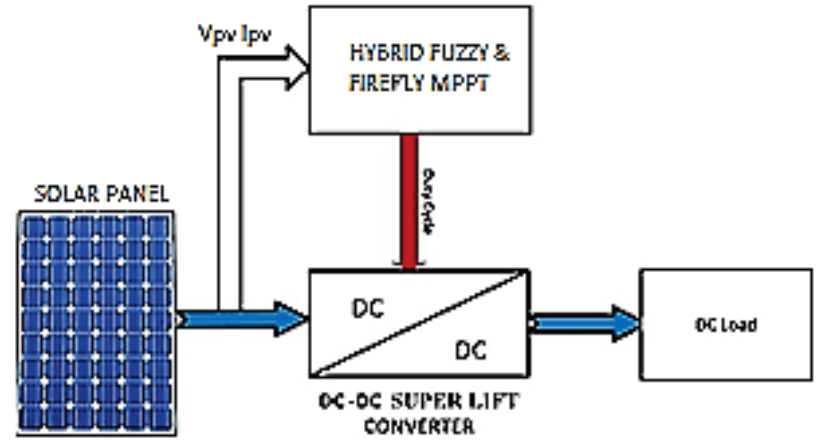

Figure 12 Hybrid firefly and fuzzy based MPPT 
The FLC has two inputs such as PV voltage and PV current as well as one output signal such as duty cycle of PWM generator. The fuzzy controller has one output signal such as duty cycle of PWM generator. The fuzzy output signal is converted from the crisp set into a fuzzy set by using the trapezoidal method. Fuzzy interference rules are developed, using IF-THEN condition, after designing input and output membership function of the proposed controller. Finally, the fuzzy controller output signal (duty cycle $-d_{\max }$ ) is fed to firefly controller. Fix the constants of firefly algorithm, namely $\beta_{\mathrm{o}}, \gamma, m, \alpha$, population size $N$ as below [16].

$$
\beta(r)=\beta_{\mathrm{o}} \mathrm{e}^{\left(-\gamma r^{m}\right)}, m>1
$$

where: $\beta_{0}$ - initial attractiveness, $\gamma$ - light intensity, $\alpha$ random movement factor, $r$ is distance between two fireflies using Cartesian distance. The projected technique regulates the super-lift boost converter in the optimum duty cycle operation which relates to MPP. By using the following steps, the required MPPT has been achieved.

1) Step 1: Initialization of $\beta, \alpha$ and population size $N$. Here the duty cycle of converter is denoted as a position of firefly.
2) Step 2: The firefly 1 moves to firefly 2 to attain the maximum brightness.

3) Step 3: Repeat the operation of the projected technique till the required maximum brightness.

4) Step 4: The optimization procedure repeats till the final iteration

In this projected technique, the level of the Firefly is considered as a duty cycle $d$ of the super lift boost converter. The brightness of every firefly is assigned as spawned power $P_{\mathrm{PV}}$ of the PV system, corresponding to the position of this firefly. The fireflies are marked in the permissible limit of the duty minimum $\left(d_{\min }\right)$ to duty maximum $\left(d_{\max }\right)$.

\section{RESULTS AND DISCUSSION}

The proposed strategy has been modeled using MATLAB / Simulink for the PV based super lift boost converter with different MPPT controllers. By choosing all inductors and capacitors, values such as $0,1 \mathrm{mH}, 0,1 \mathrm{mF}, R$ $=10 \Omega, q=1$ and $f=3 \mathrm{kHz}$ are used in the simulation environment.

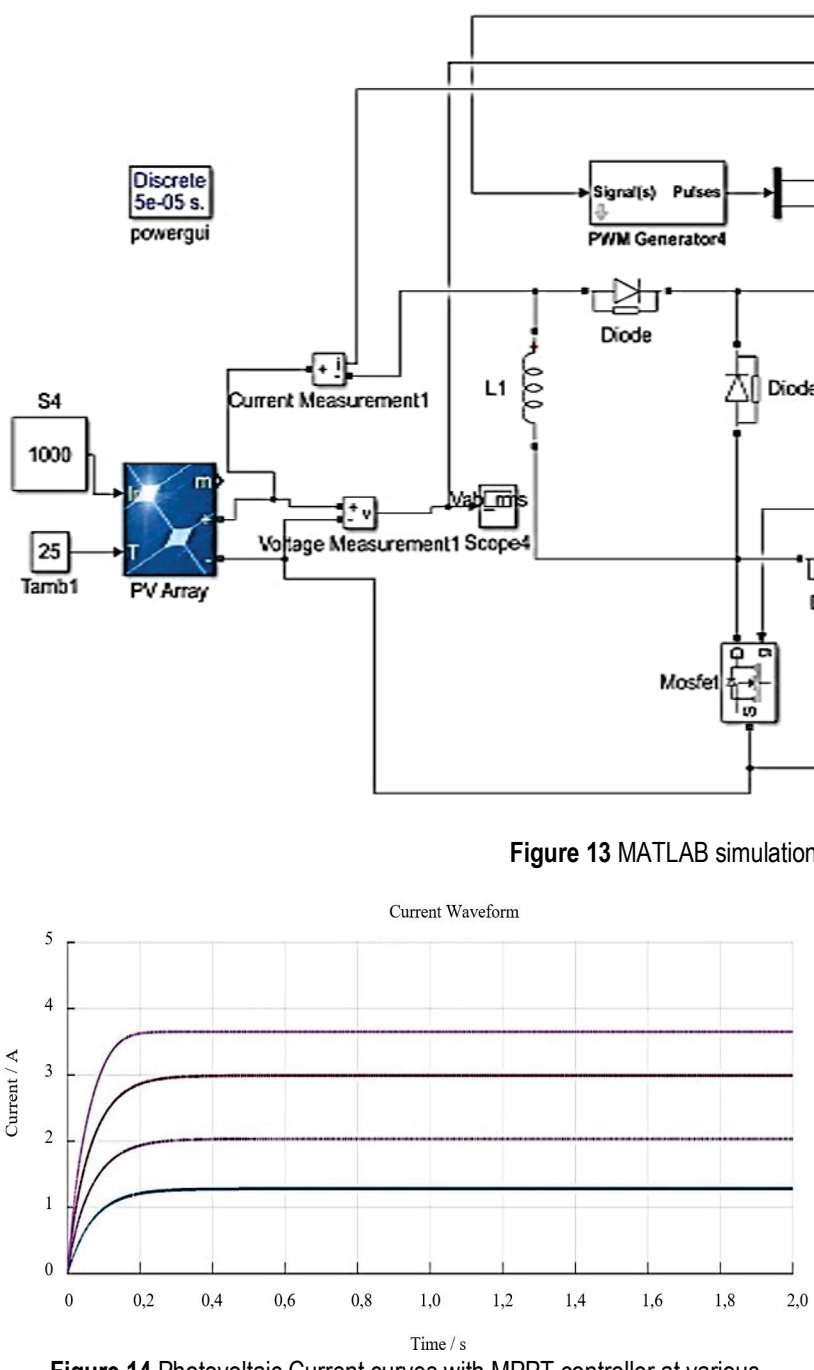

Figure 14 Photovoltaic Current curves with MPPT controller at various Irradiations

\section{Fuzzy - MPPT}

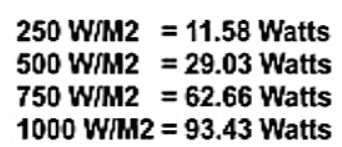

1000 WIM $=03.43$ Watts

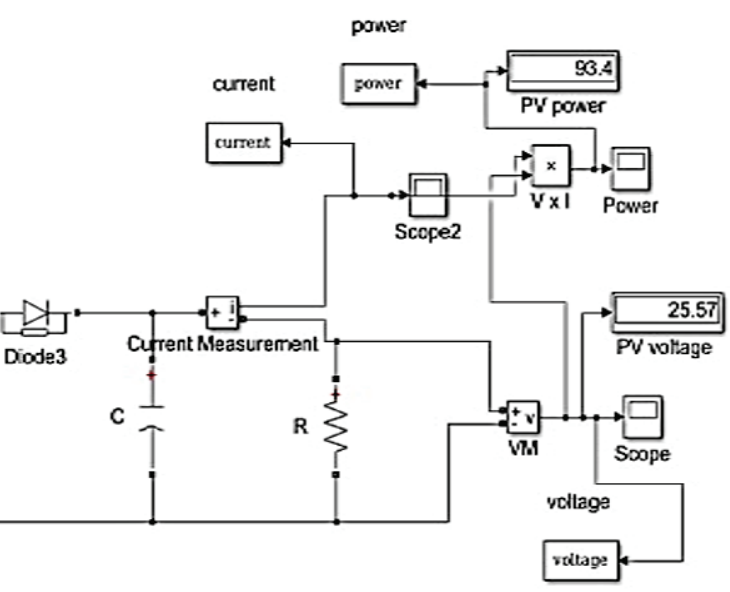

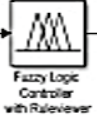
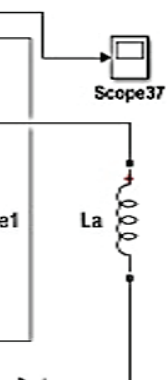
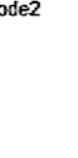

model using super- lift boost converter

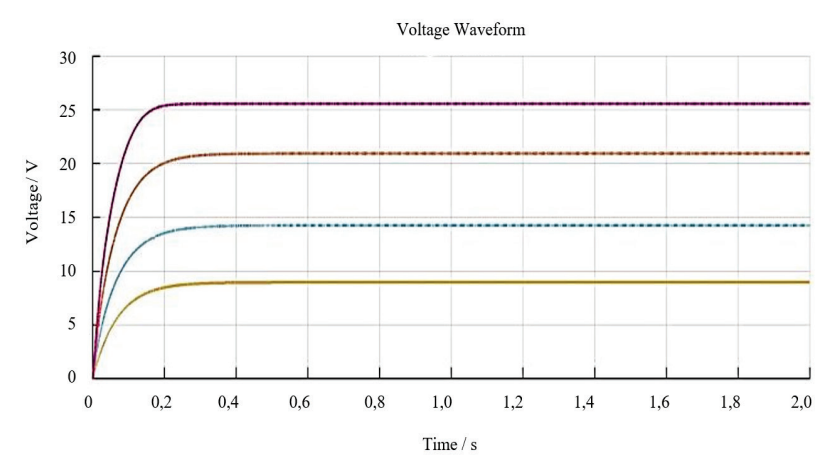

Figure 15 Photovoltaic Voltage curve with MPPT controller at various Irradiations 


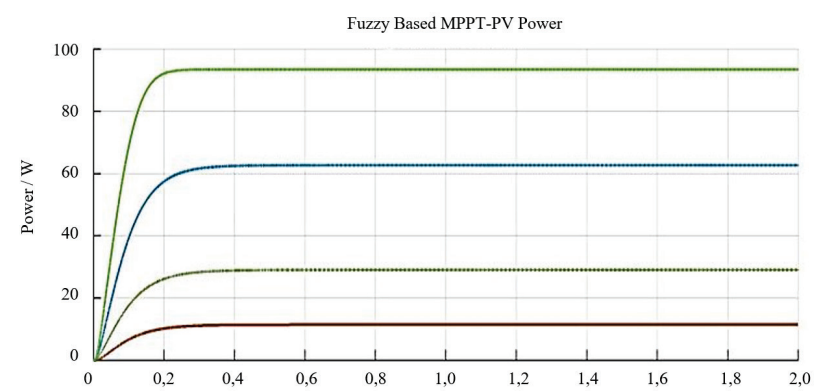

Figure 16 Photovoltaic Power curve with MPPT controller at various Irradiations

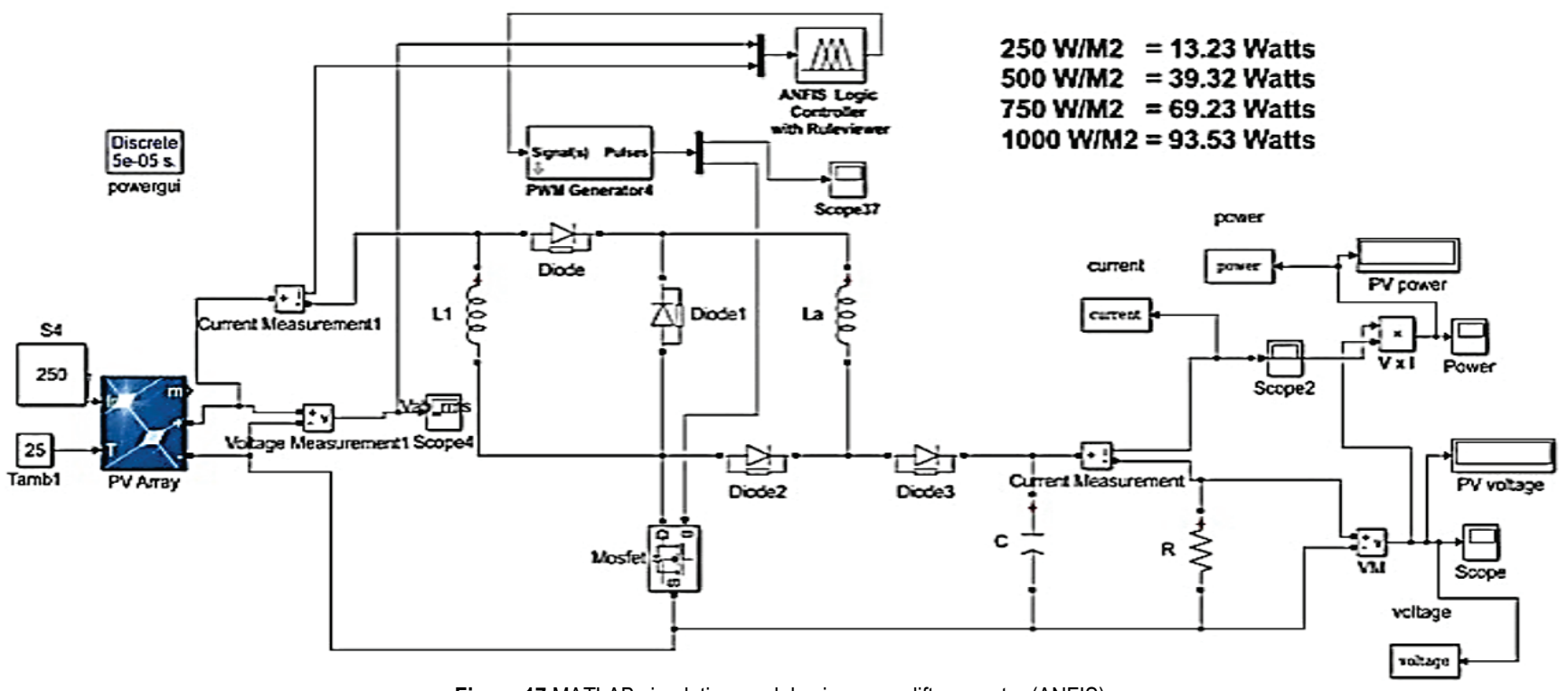

Figure 17 MATLAB simulation model using super lift converter (ANFIS)

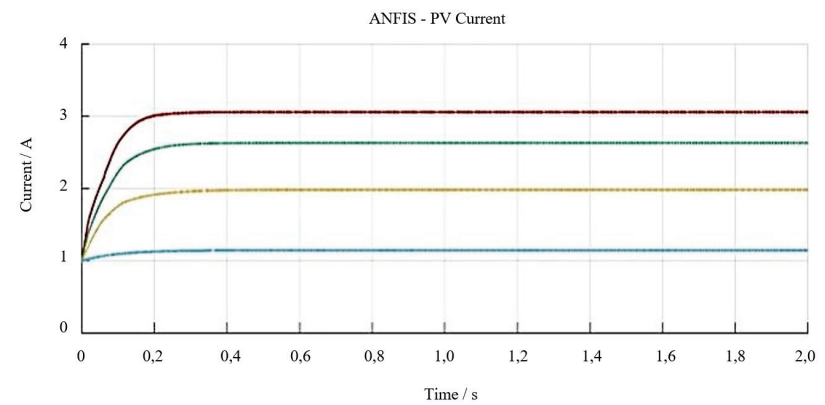

Figure 18 Photovoltaic current curves with MPPT controller at various

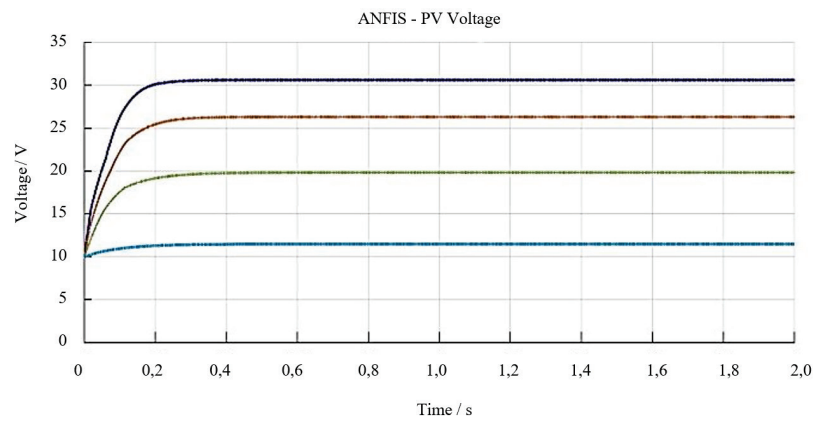

Figure 19 Photovoltaic voltage curve with ANFIS - MPPT controller at various Irradiations

The proposed ANFIS control based MPPT of DC-DC super lift boost converter has been developed in MATLAB environmental for 100 watts PV panel as shown in Fig. 17. Irradiations (ANFIS)
The proposed fuzzy logic control based MPPT of DCDC super lift converter has been developed in MATLAB environment for 100 watts PV panel as shown in Fig. 13. The proposed MPPT control of super lift boost converter has been simulated and analysed with different irradiance condition such as $250 \mathrm{~W} / \mathrm{m}^{2}, 500 \mathrm{~W} / \mathrm{m}^{2}, 750 \mathrm{~W} / \mathrm{m}^{2}$, and $1000 \mathrm{~W} / \mathrm{m}^{2}$. The simulation results of current, voltage and power are presented in Fig. 14, Fig. 15 and Fig. 16.

\section{ANFIS - MPPT}

The proposed MPPT control of super lift converter has been simulated and analyzed with different irradiance conditions such as $250 \mathrm{~W} / \mathrm{m}^{2}, 500 \mathrm{~W} / \mathrm{m}^{2}, 750 \mathrm{~W} / \mathrm{m}^{2}, 1000$ $\mathrm{W} / \mathrm{m}^{2}$. The simulation results of current, voltage and power are presented in Fig. 18, Fig. 19 and Fig. 20.

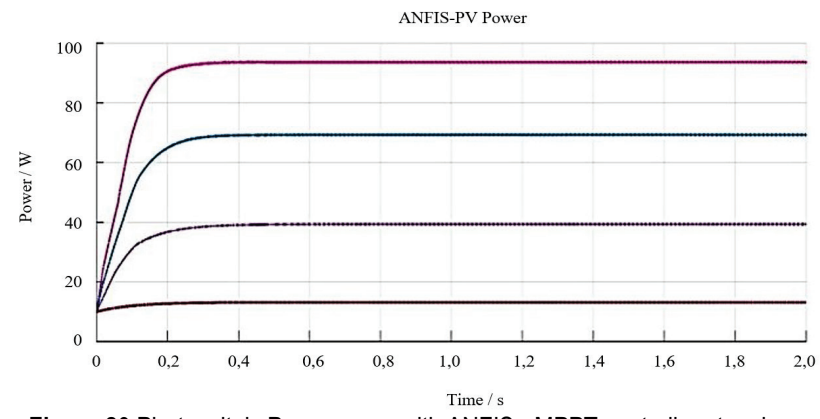

Figure 20 Photovoltaic Power curve with ANFIS - MPPT controller at various Irradiations

The proposed hybrid fuzzy and firefly control based MPPT of DC-DC super lift boost converter has also been developed in MATLAB environmental for 100 watts PV panel as shown in Fig. 21 and Fig. 22. The proposed MPPT control of Super lift converter has been simulated and analyzed with different irradiance condition such as 250 $\mathrm{W} / \mathrm{m}^{2}, 500 \mathrm{~W} / \mathrm{m}^{2}, 750 \mathrm{~W} / \mathrm{m}^{2}, 1000 \mathrm{~W} / \mathrm{m}^{2}$. The simulation results of current, voltage and power are presented in Fig. 23, Fig. 24 and Fig. 25. 


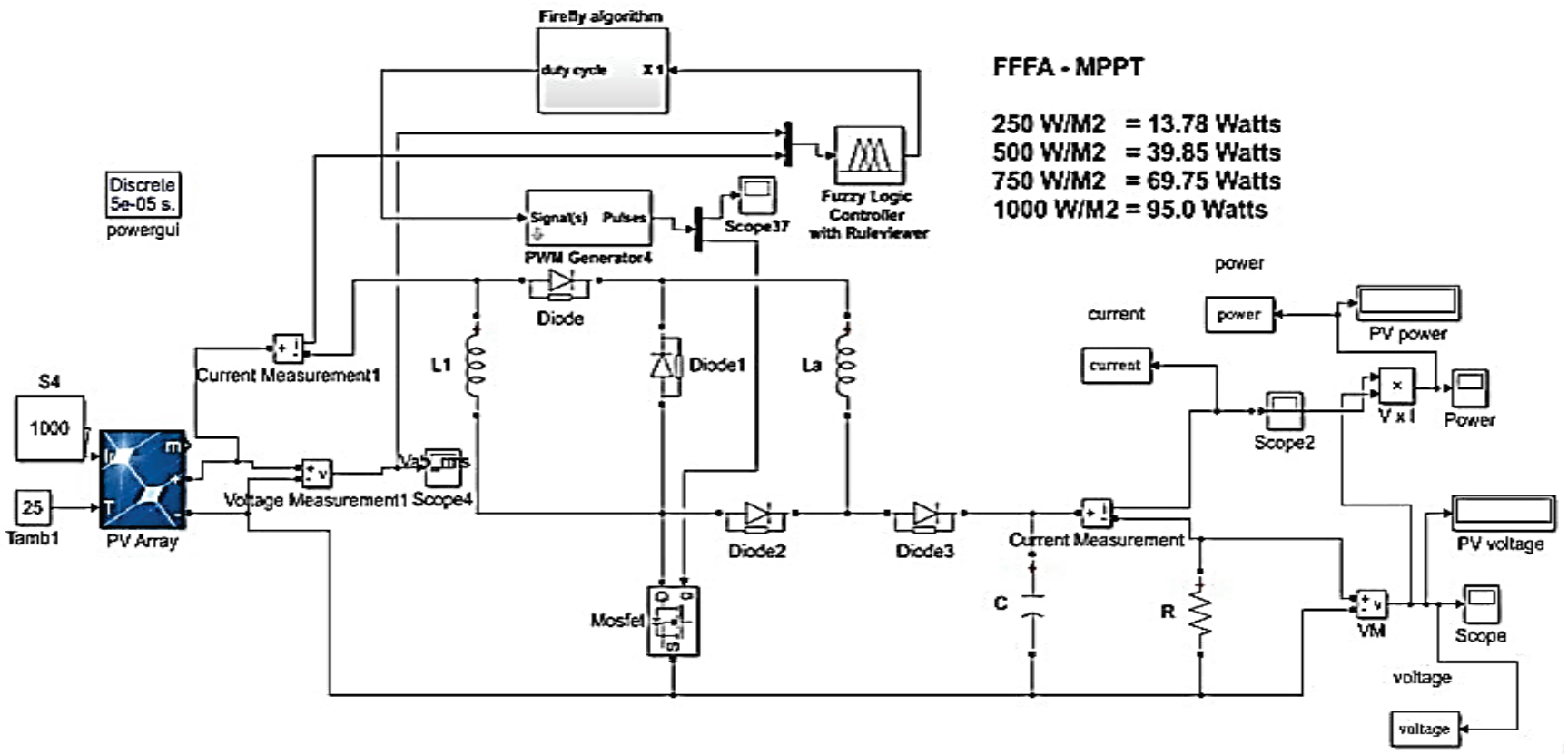

Figure 21 MATLAB simulation model using super lift boost converter (HFFFA)

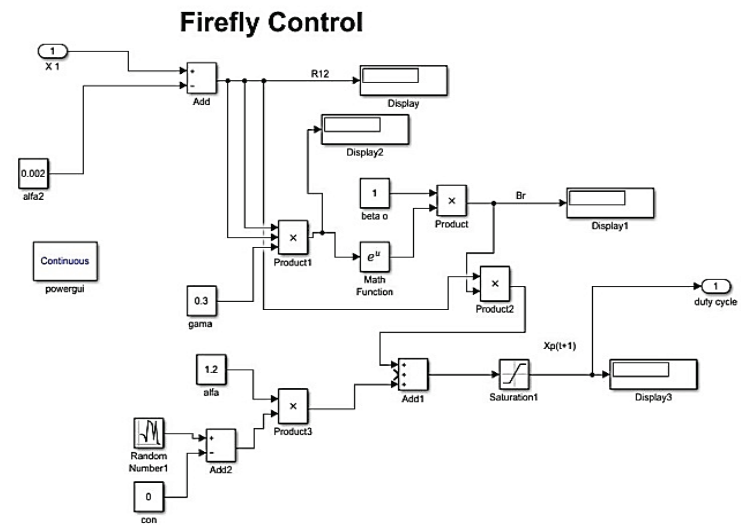

Figure 22 Firefly Controller model for MPPT

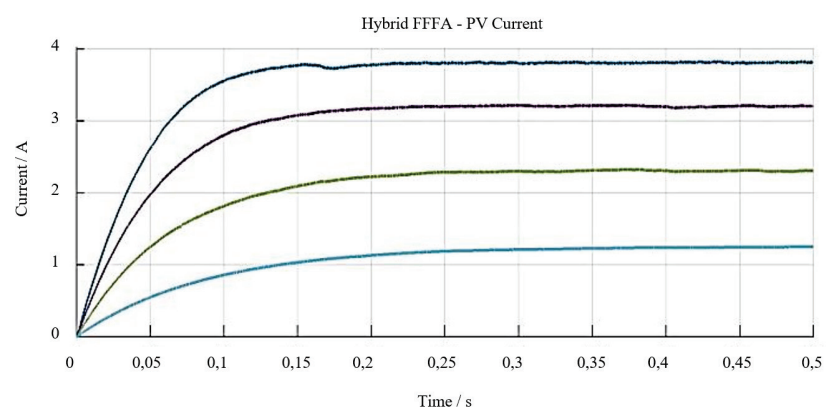

Figure 23 Photovoltaic current curve with HFFFA -MPPT controller at various Irradiation

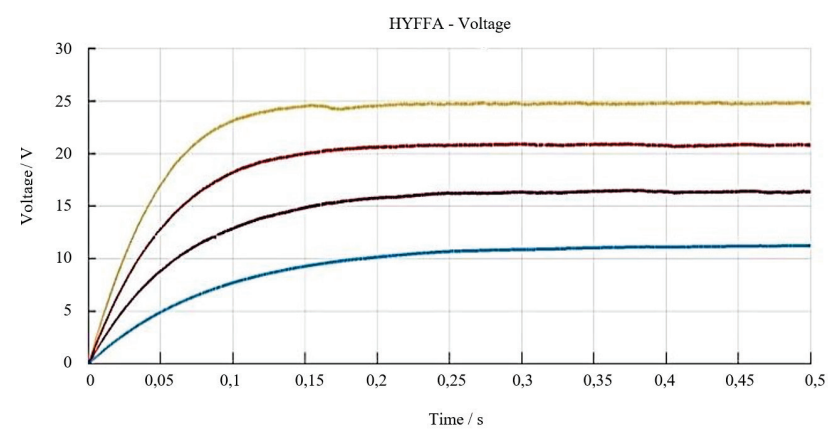

Figure 24 Photovoltaic Voltage curve with HFFFA - MPPT controller at various Irradiations

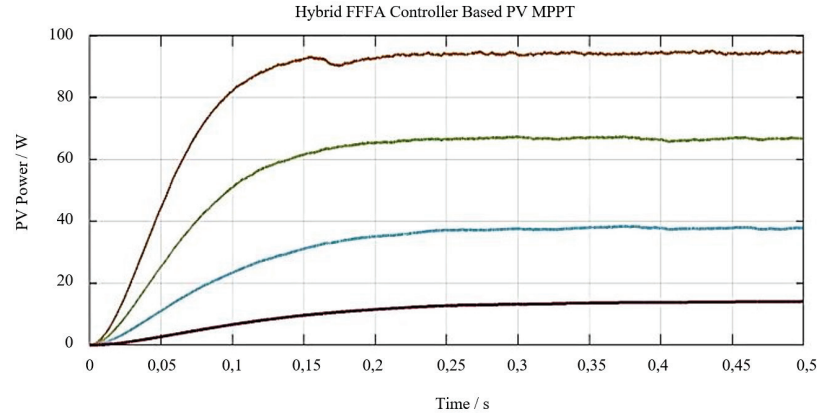

Figure 25 Photovoltaic power curve with HFFFA - MPPT controller at various Irradiations

Table 2 Comparative analysis of different MPPT Controllers

\begin{tabular}{|c|c|c|c|}
\hline $\begin{array}{c}\text { Irradiation } \\
/ \mathrm{W} / \mathrm{m}^{2}\end{array}$ & $\begin{array}{c}\text { Fuzzy based MPPT } \\
\text { of Super lift } \\
\text { converter } \\
/ \mathrm{W}\end{array}$ & $\begin{array}{c}\text { ANFIS } \\
\text { MPPT of Super } \\
\text { lift converter } \\
/ \mathrm{W}\end{array}$ & $\begin{array}{c}\text { Hybrid Firefly } \\
\text { and Fuzzy } \\
\text { MPPT of Super } \\
\text { lift converter } \\
/ \mathrm{W}\end{array}$ \\
\hline 250 & 11,58 & 13,23 & 13,78 \\
\hline 500 & 29,30 & 39,32 & 39,85 \\
\hline 750 & 62,66 & 69,23 & 69,75 \\
\hline 1000 & 93,43 & 93,53 & 95,00 \\
\hline
\end{tabular}

\section{CONCLUSION}

The proposed work has been discussed with a high gain DC-DC super-lift boost converter. This converter has been investigated for photovoltaic applications. The proposed super lift boost converter with an intelligent controller based MPPT has simulated for 100 Watts PV system in MATLAB / Simulink. The modelled system was tested with the different weather (irradiance) conditions. Thereby, the obtained results were compared with Fuzzy, ANFIS and Hybrid fuzzy and firefly based MPPT. The comparative analysis of different intelligent controller based MPPT performances is presented in Tab. 2. The obtained results using various MPPT in the super-lift boost converter show that the converter has a high gain conversion with reduced ripple voltage in the output. Based on the investigation the result obtained using MATLAB / Simulink for the proposed SLBC with different MPPT 
shows that the Hybrid Fuzzy and Firefly algorithm is more superior to the Fuzzy and ANFIS.

\section{REFERENCES}

[1] Al Nabulsi, A. \& Dhaouadi, R. (2012). Efficiency Optimization of a DSP-Based Standalone PV System Using Fuzzy Logic and Dual-MPPT Control. IEEE Transactions on Industrial Informatics, 8(3), 573-584. https://doi.org/10.1109/TII.2012.2192282

[2] Rajesh, R. \& Mabel, M. C. (2015), A comprehension review of photovoltaic systems. Renewable and sustainable Energy Rev, 51, 231-248. https://doi.org/10.1016/j.rser.2015.06.006

[3] Subudhi, B. \& Pradhan, R. (2013). A.Comparative study on maximum power point tracking techniques for photovoltaic power systems. IEEE Transactions on Sustainable Energy, 4, 89-98. https://doi.org/10.1109/TSTE.2012.2202294

[4] Ammasai, G. N., Sabitha, A. P., Hiaja, N., \& Krithiga, S. (2009). Fuzzy logic controller with MPPT using line commutated inverter for three phase grid connected photovoltaic systems. Ren. energy Elsevier, 34, 909-915. https://doi.org/10.1016/j.renene.2008.05.039

[5] Adel, M. \& Kalogirou, S. A. (2011). ANFIS-based modeling for photovoltaic power supply system: A case study. Energy, 1, 250-258. https://doi.org/10.1016/j.renene.2010.06.028

[6] Rebhi, M., Benatillah, A., Sellam, M., \& Kadri, B. (2013). Comparative Study of MPPT Controllers for PV System Implemented in the Southwest of Algeria. Energy Procedia, 36, 142-153. https://doi.org/10.1016/j.egypro.2013.07.017

[7] Saravanan, S. \& Ramesh, B. N. (2016). RBFN based MPPT algorithm for PV system with high step up converter. Energy Conversion and Management, 239-251. https://doi.org/10.1016/j.enconman.2016.05.076

[8] Dileep. G. \& Singh, S. N. (2017). Application of soft computing techniques for maximum power point tracking of SPV system. Solar energy, 141, 182-202. https://doi.org/10.1016/j.solener.2016.11.034

[9] Fang, L. L. \& Hong, Y. (2014). Super-lift boost converters. IETPow. Elec., 7, 1655-1664. https://doi.org/10.1049/iet-pel.2012.0531

[10] Luo, F. L. (2011). Investigation on Split-Capacitors applied in positive output Super-Lift Luo-Converters. Chinese Control and Decision Conference (CCDC), Mianyang, 2792-2797. https://doi.org/10.1109/CCDC.2011.5968686

[11] Shan, Z. L., Liu, S., \& Luo, F. L. (2012). Investigation of a Super-Lift Luo-Converter used in solar panel system. China International Conference on Electricity Distribution (CICED), 1-4. https://doi.org/10.1109/CICED.2012.6508606

[12] Anandhakumar, Venkateshkumar, M. \& Shankar, P. (2013). Intelligent controller based MPPT method for the Photovoltaic power system. 2013 International Conference on Human Computer Interactions (ICHCI), Chennai, 1-6. https://doi.org/10.1109//CHCl-IEEE.2013.6887790

[13] Bendib, F., Krim, H., Belmili, M., Almi, F., \& Bolouma, S. (2014), An intelligent MPPT approach based on neuralnetwork voltage estimator and fuzzy controller, applied to a stand-alone PV system. IEEE $23^{\text {rd }}$ International Symposium on Industrial Electronics (ISIE), Istanbul, 404-409. https://doi.org/10.1109/ISIE.2014.6864647

[14] Muttath, M. H. \& Baburaj, P. (2015). Interleaved Luo converter for the residential PV grid connected systems. $10^{\text {th }}$ Asian Control Conference (ASCC), Kota Kinabalu, 1-6. https://doi.org/10.1109/ASCC.2015.7244703

[15] Ajiatmo, D. \& Robandi, I. (2016). A hybrid Fuzzy Logic Controller-Firefly Algorithm (FLC-FA) based for MPPT Photovoltaic (PV) system in solar car. IEEE International Conference on Power and Renewable Energy (ICPRE), 606610. https://doi.org/10.1109/ICPRE.2016.7871149
[16] Chen,W., Yang, L., Liu, W., Wang, Y., \& Wang, D. (2016). MPPT control of small permanent magnet direct-drive wind power generation based on FASVR method. IEEE Chinese Guidance, Navigation and Control Conference (CGNCC), 1840-1844. https://doi.org/10.1109/CGNCC.2016.7829069

[17] Windarko, N. A., Tjahjono, A., Anggriawan, D. O., \& Purnomo, M. H. (2015). Maximum power point tracking of photovoltaic system using adaptive modified firefly algorithm. International Electronics Symposium (IES) / Surabaya, 31-35. https://doi.org/10.1109/ELECSYM.2015.7380809

[18] Chakrabarti, T., Sharma, U., Manna, S., Chakrabarti, T., \& Sarkar, S. K. (2015). Design of intelligent Maximum Power Point Tracking (MPPT) technique based on swarm intelligence based algorithms. International Conference on Power and Advanced Control Engineering (ICPACE) Bangalore, 173-177. https://doi.org/10.1109/ICPACE.2015.7274938

[19] Nugraha, S. D., Wahjono, E., Sunarno, E., Anggriawan, D. O., Prasetyono, E., \& Tjahjono, A. (2016). Maximum power point tracking of photovoltaic module for battery charging based on modified firefly algorithm. International Electronics Symposium (IES) / Denpasar, 238-243. https://doi.org/10.1109/ELECSYM.2016.7861009

[20] Allataifeh, A. A., Bataineh, K., \& AI-khedher, M. (2015). Maximum Power Point Tracking Using Fuzzy Logic Controller under Partial Conditions. Smart Grid and Renewable Energy, 6, 1-13. https://doi.org/10.4236/sgre.2015.61001

[21] Yang, X. (2009). Firefly algorithms for multimodal optimization in: Stochastic Algorithms: Foundations and Applications. Lecture Notes in Computer Sciences, 5792, 169-178. https://doi.org/10.1007/978-3-642-04944-6_14

[22] Aji, S., Robandi, D., \& Suryoatmojo, H. (2013). MPPT Based on Fuzzy Logic Controller (FLC) for Photovoltaic (PY) System in Solar Car. Mechatronics / Electr. Power, Veh. Technol., 4, 127-134. https://doi.org/10.14203/j.mev.2013.v4.127-134

Contact information:

Palanivel MANIKANNAN, Assistant Professor,

(Corresponding author)

A.K.T. Memorial College of Engineering and Technology,

Kallakuruchi, Tamilnadu, India-606 202

E-Mail: p.manikannan@gmail.com

Kaithmalai UDHAYAKUMAR, Professor,

College of Engineering, Guindy,

Anna University, Chennai-600025, India-606 202

E-mail: k.udhaya@gmail.com

Parthasarathi PUGAZHENDIRAN, Professor,

IFET College of Engineering, Villupuram,

Tamilnadu, India-605108

E-mail: pugazh.ceg@gmail.com 